\title{
解析高级经济师人力资源管理发展的现状及对策
}

\author{
间嘉伟 \\ 河北省承德县医疗保障局 \\ DOI:10.12238/ej.v3i4.483
}

\begin{abstract}
[摘要] 当前我国市场经济正在深入发展, 这就导致各行业竞争压力与日俱增,尤其是在当前这一发展 形势下,各企业间的竞争更是如火如茶。当前各企业竞争的关键点已经不在于市场占有量,转而是人才竞 争成为了提高企业竞争力的重要因素。所以各企业在发展中若要提高自身行业竞争力,保证在行业中能 够扎根立足,那么在工作中就要优化人力资源管理工作, 以保证在实际工作中能够为企业带来高素质人 才。由此可见高级经济师在企业运行中有着多么重要的影响, 本文就针对高级经济师人力资源管理发展 的现状及对策进行深入分析。
\end{abstract}

[关键词] 高级经济师; 人力资源管理；发展现状；有效对策

中图分类号: C962 文献标识码: A

在当前市场经济发展中, 企业能否 稳定运行与人力资源管理工作有着重要 联系, 那么在企业发展过程中人力资源 管理部门应怎样合理调配人力资源就成 为了相关工作人员需要认真分析的一 点。在我国全球化发展背景下,企业人力 资源传统管理方式已经无法帮助企业稳 定运行, 所以在发展过程中相关工作人 员就要提高专业素养, 进而在工作中将 人力资源管理工作价值展现出来, 使企 业可以步入健康稳定的发展进程中。

1 新时代高级经济师人力资源 管理战略的重要意义

1. 1 是企业战略的核心

任何企业的发展都需要完善的竞争 策略才能保证企业稳定运行, 那么在企 业竞争战略中人力资源管理战略就是其 中重要的组成部分, 可是在实际管理过 程中这一发展战略又偏向于人才培养, 因此这一工作就具有十分特殊的意义, 所以为了保证人力资源战略能够有效开 展, 各企业就需要专业能力过硬的高级 经济师, 进而在工作中有效提高人力资 源管理效率 ${ }^{[1]}$ 。

\section{2 可提高企业的效益}

在企业发展中人才是支撑企业稳定 运行的基础, 因为在企业运行中无非就 是与客户以及经济效益打交道, 所以在
企业运行中若是可以将人才安排到合适 的岗位中, 那么人才为企业带来的经济 效益就会翻倍。那么在人力资源管理中 高级经济师就是保证人力资源管理有效 开展的专业人才, 在人力资源管理中需 要涉及到大量专业工作内容, 并且这些 专业工作的开展又与高级经济师有着密 切联系, 所以在企业运行中管理部门就 要将高级经济师人才重视起来。

\section{2 高级经济师人力资源管理的} 现状

2.1 人力资源管理模式过于落后

在当前社会与经济发展背景下, 企 业人力资源管理可谓是发生了翻天覆地 的变化, 无论是在工作流程上还是在管 理模式中, 企业人力资源管理都随着市 场变化在革新。但是反观当前大部分企 业的人力资源管理模式, 很多企业在管 理过程中还在利用老套的方式开展着工 作, 这就导致在人力资源管理工作开展 过程中, 大部分工作内容都已经无法为 企业运行带来帮助, 甚至部分工作内容 根本就无法为企业带来经济效益, 使得 企业在开展人力资源管理工作时十分被 动。所以在发展过程中企业管理人员就 要将这一问题重视起来, 进而在发展过 程中将现代化人力资源管理方式应用起 来, 同时改变高级经济师人力资源管理
观念, 保证企业在开展人力资源管理工 作时能够获得一定效益 ${ }^{[2]}$ 。

\section{2 人力资源管理需要创新}

在当前这一新时代发展背景下, 企 业若想在行业中扎根立足, 那么就要在 提高企业自身内涵的基础上对人力资源 管理工作进行优化。进而在发展过程中 保证在人力资源管理工作的帮助下能够 提高客户满意度, 同时保证企业经济效 益得到提升。因此在实际管理与优化过 程中各企业就要通过以下几点开展工作, 首先在优化前企业管理人员一定要明确 发展方向, 并且制定相应的发展目标以 及规划, 其次就是要在发展过程中明确 企业主要经济效益来源, 进而针对能够 提高企业经济效益的环节来落实各项优 化工作, 最后就是要在优化过程中对企 业人力资源管理机制进行整理, 同时还 要对相关工作人员的管理职责进行确 认。这样企业在发展过程中才能保证人 力资源管理工作有效开展, 进而在发展 中对人力资源管理工作进行创新, 保证 企业可以健康稳定发展。

3 有效解决高级经济师人力资 源管理现状问题的对策

3.1建立完善的责任制度

企业若想在当前这一市场竞争如此 理解的环境中扎根立足, 那么就需要通 
过高级经济师专业的人力资源管理工作 来开展工作, 以保证在企业运行过程中 高级经济师可以帮助企业挑选出专业人 才, 进而提高企业行业竞争力。那么在发 展中企业管理人员就要在发展中将高级 经济师的重要性展现出来, 并在其工作 中制定相应的责任制度来规范高级经济 师工作, 保证在企业运行中高级经济师 能够做到尽职尽责, 使高级经济师可以 通过制度的限制融入到企业日常工作 中。例如企业管理人员可以为高级经济 师制定奖惩措施, 并明确高级经济师考 核规范与提成内容, 通过对高级经济师 综合能力的分析来提高其工作质量, 保 证企业在发展中可以通过高级经济师的 工作提高自身行业竞争力。不仅如此, 企业在发展中还可以针对整体运行方向 以及企业实际情况为高级经济师提供相 应的专业培训, 以保证高级经济师在培 训过程中能够更加充分的了解到企业发 展目标, 进而提升高级经济师专业水准 以及工作效率, 使高级经济师的任何工 作都可以围绕企业竞争力提升来开展, 以展现出企业高级经济师存在的价值, 同时提高企业专业人才质量 ${ }^{[3]}$ 。

3.2 增强管理者竞争意识

在当前高学历、高才能人才数量不 断提升的今天, 科学技术成为了企业稳 定运行与发展的基本要素, 同时科学技 术的应用对于高级经济师人力资源管理 工作也有着十分深远的影响。那么在企 业发展过程中管理人员就要将这一技术 应用到日常工作中, 同时利用科学技术 来提高企业内部竞争程度, 以保证企业 员工在日常工作中能够提高竞争意识。
所以高级经济师就成为了企业人力资源 管理工作中的重要影响因素, 高级经济 师在工作中就要融入到企业发展规划中, 进而在企业发展过程中提升自身的专业 能力与竞争意识, 以保证在工作中能够 将竞争意识带入到人力资源管理中, 进 而提高企业所有员工的工作积极性, 使 员工可以做到与企业发展共同进步。例 如某企业在发展中需要聘请新员工并培 训, 以保证新员工在进入企业后就可以 有效开展各项工作, 那么高级经济师在 进行人力资源管理工作时就要组织新员 工与部门老员工进行交流, 进而帮助新 员工快速掌握部门工作基本状况。不仅 如此, 高级经济师在工作中还要对新员 工进行企业文化培训, 以保证新员工在 工作中可以践行企业文化做到与企业协 同发展。

3. 3优化管理者管理水平

人才质量是影响企业稳定发展主要 因素之一, 那么企业高级经济师在进行 人力资源管理时就要将这一问题重视起 来, 并在工作中不断提高自身专业能力, 与此同时, 企业在发展中也要重视高级 经济师专业能力提升的重要性。这样才 能保证高级经济师在企业发展过程中能 够满足企业需求, 同时保证高级经济师 在工作中能够根据企业发展来开展相关 工作。那么企业在发展中就要通过以下 几点来提升高级经济师人力资源管理水 准, 首先在管理过程中企业管理人员就 要改变传统高级经济师人力资源管理工 作理念, 以保证高级经济师可以通过不 断的总结来提高自身思想观念, 使高级 经济师可以在工作中将企业发展方向作
为职业发展以及工作的核心。其次就是 在工作中要不断对高级经济师进行培训, 并为其提供专业的提升环境, 保证高级 经济师在工作中能够将现代化的管理方 式应用到企业人力资源管理工作中。最 后就是要不断扩充企业内部高级经济师 管理团队, 并在发展过程中将更多专业 人才聘请到企业中, 以通过新鲜血液的 融入来提高人力资源管理团队的工作质 量 ${ }^{[4]}$ 。

\section{4 结束语}

通过以上总结可以看出, 在当前新 时代背景下, 各企业在发展中一定要将 高级经济师的人力资源管理工作重视起 来, 并在发展过程中对高级经济师的专 业能力进行提升, 以保证高级经济师在 工作中可以有效提高人力资源管理效率, 同时还可以保证在工作中高级经济师可 以将企业员工的工作积极性调动起来。 最终通过高级经济师的人力资源管理工 作来推动企业稳定发展, 保证企业可以 在行业与社会发展中扎根立足。

\section{[参考文献]}

[1]千洁琳.浅论高级经济师人力资 源管理发展现状及对策 [J]. 市场周 刊・理论版,2018,(39):42.

[2]朱克敏.新时代高级经济师人力 资源管理战略研究 [J]. 市场周刊・理论 版,2019,(26):206-207.

[3]曹波.新时代高级经济师人 力资源管理战略研究 [J]. 经营者, 2019,33(11):131.

[4]周丹.浅谈高级经济师人力资源 管理发展的现状及对策 [J]. 记者观察: 中,2018,(5):125. 